in a different category. No controlled trial with a paratyphoid A vaccine has yet been reported, and in at least two trials paratyphoid B vaccine has been ineffective. ${ }^{6}$

It has been suggested that a monovalent vaccine would be preferable to a multivalent. W.H.O. experts affirm that it does not seem advisable to add to typhoid antigen (which is potent and effective) an antigen of doubtful effectiveness that adds to the reaction in the vaccinated person but does not necessarily add to the protection against typhoid fever. ${ }^{7}$ In the U.S.A. also there is a trend to change from T.A.B. to a typhoid vaccine ${ }^{8}$ paratyphoid vaccines are thought there to be ineffective and to increase the incidence of reactions. ${ }^{9}$ This is perhaps a challenge to the pharmaceutical industry in the United Kingdom to make a potent monovalent vaccine. An acetoneinactivated and acetone-dried vaccine is marginally more effective than the traditional heat-killed and phenolized preparation, but this might or might not be commercially feasible. All things considered, it does not at present seem essential to discard our time-honoured and successful T.A.B. vaccine.

As to dosage, some have suggested that three doses are unnecessary and that one dose is sufficient to give protection. This may be wishful thinking. The reason why, for example, one dose of a potent typhoid vaccine was as effective as two doses in Guyanese children ${ }^{10}$ was probably that the inhabitants of that area, where typhoid is endemic, had previously ingested subinfective doses of typhoid and related organisms, so that the vaccine was actually a secondary stimulus to a latent immunity. There can be no justification for assuming that in Britain there is any basal immunity to enteric infections. Two doses of T.A.B. vaccine are therefore necessary for protection, and three doses are even better.

The reaction to T.A.B. inoculation is sometimes troublesome, and any means of reducing it is welcome. Probably the most successful method is to give the vaccine intradermally. ${ }^{11} 12$ It is generally agreed that an intradermal dose of $0.1 \mathrm{ml}$. is as effective as a subcutaneous or intramuscular dose of $0.5 \mathrm{ml}$. The British Army has for many years given its T.A.B. (usually combined with tetanus vaccine as T.A.B.T.) intradermally with great success. ${ }^{13}$

What advice, then, should be given on T.A.B. inoculations to travellers going abroad on holiday? Those who have never had any anti-typhoid immunization should have the full course of three inoculations-two doses before travelling, with insistence that the third dose is necessary in 6-12 months' time. Persons who have had the full course three years or more previously should be given two doses of T.A.B. vaccine, with an interval between them of 4-6 weeks. The traveller who leaves his immunization until a week or two before departure should be given one dose of T.A.B.-not two doses

1 British Medical fournal, 1969, 3, 605.

2 Yugoslav Typhoid Commission, Bulletin of the World Health Organization, 1964, 30, 623.

3 Typhoid Panel, U.K. Department of Technical Co-operation, Bulletin of the World Health Organization, 1964, 30, 631.

4 Hejfec, L. B., Bulletin of the World Health Organization, 1965, 32, 1.

Polish Typhoid Committee, Bulletin of the World Health Organization, 1966, 34, 211 .

6 Standfast, A. F. B., British Medical Bulletin, 1969, 25, 189.

7 Cvjetanovic, B., and Uemura, K., Bulletin of the World Health Organization, 1965, 32, 29.

8 U.S. Department of Health, Education and Welfare; Advisory Committee on Immunization Practiçes, Morbidity and Mortality Weekly Report, 1966, 15, 247.

- Kline, S. A., Fournal of Occupational Medicine, 1968, 10, 285.

10 Ashcroft, M. T., et al., Lancet, 1967, 2, 1056.

1 Barr, M., Sayers, M. H. P., and Stamm, W. P., Lancet, 1959, 1, 816.

12 Noble, J. E., Fournal of the Royal Army Medical Corps, 1963, 109, 178.

13 Ministry of Defence, Memorandum on Immunological Procedures, 4th ed., London, H.M.S.O. 1968.

14 Medical Officer, 1970, 123, 12 within 10 days-and reminded that he should have the second dose on his return from holiday. Those who have had the full course of three inoculations within the previous three years require only one reinforcing dose of T.A.B. vaccine.

For the reinforcement of immunity it is logical to assume that, after primary immunization or after a reinforcing dose of vaccine, protection is maintained for at least one year and basal immunity exists for three years. Persons at risk (as holiday travellers generally are) require a reinforcing dose ever year, while those not at risk (persons remaining in this country) should receive this only every third year. It is advisable for people who only occasionally go to places where they may be exposed to typhoid infection to keep their basal immunity "topped up" in order to circumvent the necessity, when they do decide to travel, of undertaking primary immunization afresh. Likewise, the traveller who pops over to the Costa Brava every summer needs only one dose of T.A.B. each time he buys his ticket-three or four weeks before departure.

It is good to know that the Ministry of Health and Social Security is planning to issue information to travel agents and others associated with the tourist trade so that they can pass on the appropriate advice to travellers. ${ }^{14}$

\section{Surgical Treatment of Thyrotoxicosis}

Many clinicians regard subtotal thyroidectomy as the best treatment for hyperthyroidism in young adults with enlarged thyroid glands; but in different series ${ }^{1-5}$ the incidence of hypothyroidism after operation has ranged from 5 to $36 \%$ and of hyperthyroidism from 0 to $11 \%$.

The report by Dr. A. J. Hedley and his colleagues in this week's $B . M . \mathcal{F}$. (page 519) is a useful addition to our knowledge on this subject. They surveyed 254 patients treated by subtotal thyroidectomy in Aberdeen from 1946 to 1965 . Of these only $198(78 \%)$ could be identified despite a thorough search, so that the total morbidity in the series could not be accurately assessed. Data are presented on 146 of these patients operated on in the same surgical unit and followed up for $2-21$ years (mean 9.3 years) after operation. At the time of follow-up $55 \%$ of the patients were euthyroid, $5 \%$ had equivocal thyroid status, $27 \%$ had become hypothyroid and were receiving some form of replacement therapy, $10 \%$ had untreated hypothyroidism, and $4 \%$ were hyperthyroid. Thus

1 Bowers, R. F., American Surgeon, 1966, 32, 89.

Plested, W. G., and Pollock, W. F., Archives of Surgery, 1967, 94, 517.

3 Roy, A. D., Allan, J., and Harden, R. M., Lancet, 1967, 2, 684

4 McNeill, A. D., and Thomson, J. A., British Medical fournal, 1968, 3, 643. Murley, R. S., and Rigg, B. M., British fournal of Surgery, 1968, 55, 757.

Bronsky, D., Kiamko, R. T., and Waldstein, S. S., Archives of Internal Medicine, 1968, 121, 113.

8 Whitsell, F. B., and Black, B. M., fournal of Clinical Endocrinology, 1949, 9, 1202 .

9 Greene, $\mathrm{R}$., Fournal of Endocrinology, 1951, 7, 1.

10 Irvine, W. J., and Stewart, A. G., in Thyrotoxicosis, Proceedings of an International Symposium, Edinburgh, 1967, ed.W. J. Irvine, p. 111. Edinburgh, Livingstone.

11 McLarty, D. G., Alexander, W. D., Harden, R. M., and Clark, D. H., British Medical fournal, 1969, 3, 203. 
in only about one-half of the patients was the thyroid state satisfactory without medication, and the true morbidity may have been even higher, for there is some evidence that thyroid dysfunction may prevent patients from attending for follow-up.

These authors could not confirm that cases of hypothyroidism after partial thyroidectomy increase with length of follow-up, as others have shown, ${ }^{67}$ but more complete data are required to settle this point. The high incidence of hypothyroidism in this series must, at least in part, reflect the radical excision of tissue, but it may have other causes too. For example, in Iceland, where the diet is rich in iodine, radical subtotal thyroidectomy is followed by a greater incidence of hyperthyroidism and a lower incidence of hypothyroidism. Thyroiditis is known to be associated with postoperative hypothyroidism, ${ }^{89}$ and in the study by W. J. Irvine and A. G. Stewart ${ }^{10}$ about one-quarter of patients with high or moderate titres of thyroid complement-fixing antibodies became hypothyroid in the first year after operation.

Hedley and his colleagues' findings support those of D. G. McLarty and colleagues ${ }^{11}$ that there is no justification for a second operation for recurrent hyperthyroidism, since it is unlikely to render the patient euthyroid. Conventional courses of antithyroid drugs are also followed by relapse in the majority of such patients. ${ }^{11}$ Clinicians must therefore choose between long-term administration of antithyroid drugs and radioiodine therapy for patients with recurrent hyperthyroidism.

The important conclusion to be drawn from this and other long-term studies of patients treated by operation or radioiodine is that life-long follow-up is required. Hedley and colleagues have shown at the Aberdeen clinic how this can be carried out using an automated follow-up register with central data-processing facilities. They report on the scheme at page 556.

\section{Care of Mentally Retarded}

The hospital care provided for mentally retarded patients is too often a depressing contrast with what the mentally healthy receive. Ancient and isolated buildings are the common lot, with large, overcrowded wards and chronic shortage of staff. So hopelessly unappealing are the conditions to nurses that in many of these hospitals only a small minority are British-born. Yet men and women of vision are to be found among the staffs devoting their lives to the care of the mentally retarded, though their leadership cannot do more than lighten some corners of a scene whose shadows are far too readily acceptable to the general public.

More money is an urgent necessity, and the promise of some to be used solely for improvements of hospital services for the mentally handicapped is therefore a step in the right direction. On 11 February Mr. Richard Crossman, Secretary of State for Social Services, announced in a debate in Parliament that he had allocated a further $£ 3 \mathrm{~m}$. of revenue for that purpose. ${ }^{1} \mathrm{He}$ had also told the boards to make an additional flm. of capital available to the same end. So great are the real needs of the hospital services of mentally retarded people that the money now to be provided is no more than a beginning.

${ }^{1}$ British Medical fournal, 1970, 1, 508.

2 House of Commons Hansard, 11 February, 1970, col. 1355.
No doubt it will help, especially in remedying deficiencies in clothing and food to which $\mathrm{Mr}$. Crossman drew attention.

But while the Secretary of State shows his concern to improve the provision made for mentally handicapped patients Mr. Crossman the politician with votes to count cannot resist the opportunity to lay the shortcomings of the service on the medical profession. Both in the Parliamentary debate $^{2}$ and in an address last week to the National Association for Mental Health, when he used the same words, he said that "money will be wasted and the staff will become demoralized unless we can persuade the medical profession, which sets the standards, that these hospitals cannot be permitted to remain a medical backwater and dead-end to which able, ambitious, and sensible young men will not go." He should know that the medical profession does not need to be persuaded of this aim. Its members have time and again criticized the lack of resources devoted to mentally handicapped patients. The fact is that the conscience of the community as a whole has been sleeping on this issue and has ignored the real facts. Until Parliament finds adequate resources for running the Health Service it will continue to drift along on the cheap, relying excessively on labour from abroad, and faltering in some of the care it provides.

\section{Employment Medical Advisory Service}

Part 1 of the Employed Persons (Health and Safety) Bill published last week proposes the establishment under the Secretary of State for Employment and Productivity of an employment medical advisory service. Appointed factory doctors provided for by the Factories Act, 1961, would be abolished and in their place would be employment medical advisers. The main functions proposed for the new service are to inform and advise the Secretary of State on matters concerning the safeguarding and improvement of the health of employed persons. The Bill enables the Secretary of State to investigate problems in connexion with these matters and to maintain laboratories and other services.

Clause 1 (6) of the Bill reads as follows:

"It shall be the duty of every local education authority or, in Scotland, education authority to arrange for their officers to furnish, on the application of an employment medical adviser, such particulars of the school medical record of a person who has not attained the age of eighteen and such other information relating to his medical history as the adviser may require for the efficient performance of his functions."

There is a similar clause in the Factories Act, 1961, except that it states the particulars are to be furnished for the appointed factory doctor's "confidential information."

Clause 5 of the Bill provides for a new section to be inserted in the Factories Act, 1961, requiring factory occupiers to give notice of the employment of a young person to the local careers office (maintained under the Employment and Training Act, 1948) within seven days of the engagement. The present section 118, under which there is a routine medical examination of young persons by the appointed factory doctor, is to be repealed with the abolition of the appointed factory doctor. 